\title{
TREN PUBLIKASI JURNAL ILMIAH ONLINE DI UNIVERSITAS ISLAM NEGERI ALAUDDIN MAKASSAR
}

\author{
Taufiq Mathar*, A. Khaidir Akbar**, Hijrana Bahar**
}

Pengutipan: Mathar, T., Akbar, A. K., Bahar, H. (2017). Tren publikasi jurnal ilmiah online di Universitas Islam Negeri Alauddin Makassar. Khizanah al-Hikmah : Jurnal Ilmu Perpustakaan, Informasi, dan Kearsipan. (5)2, 222-231.

DOI: https://doi.org/10.24252/kah.v5i2a9

*Dosen di Jurusan Ilmu Perpustakaan UIN Alauddin Makassar (taufiq.m@uin-alauddin.ac.id)

**Perpustakaan UIN Alauddin Makassar (a.khaidirakbar@uin-alauddin.ac.id)

**Perpustakaan UIN Alauddin Makassar (hijrana.bahar@uin-alauddin.ac.id)

\section{ABSTRAK}

Penelitian ini fokus kepada tren publikasi jurnal ilmiah online yang ada di Universitas Islam Negeri (UIN) Alauddin Makassar, khususnya pada jurnal ilmiah dalam bentuk online yang dapat diakses melalui situsnya. Data-data penelitian diperoleh dari situs resmi jurnal online kampus ini, Google Cendekia (Google Scholar), PDII LIPI, dan beberapa dokumen-dokumen pendukung lainnya. Penelitian ini menunjukkan bahwa terdapat 62 jurnal ilmiah online dengan beragam subjek dan terindeks di beragam situs-situs pengindeks nasional maupun internasional. Hingga November 2017, terdapat sebanyak 2343 artikel jurnal yang telah dipublikasi secara online. Selain itu, Lentera Pendidikan, Khizanah al-Hikmah, dan Assets merupakan 3 jurnal yang memiliki sitasi, h-index, dan i10-index paling tinggi di antara jurnal-jurnal lainnya. Kata Kunci: Tren publikasi ilmiah, jurnal, faktor dampak publikasi, google scholar

\section{ABSTRACT}

The study is aimed to describe scholarly journals publication in Universitas Islam Negeri Alauddin Makassar (State Islamic University Alauddin of Makassar), particularly in online scholarly journals which can be accessed throughout its journal website. The data were gathered from its journal website, Google Scholar, PDII LIPI, and few documents from the campus. The study found that there were 62 scholarly journals within the campus which have different subjects and indexed in national or international index sites. Until November 2017, these journals have published as many as 2343 papers online. In addition, Lentera Pendidikan, Khizanah al-Hikmah, and Assets were the three most cited journals compared to others.

Keywords : Research publication trends, journal; h-index, publication impact factor, google scholar

\section{PENDAHULUAN}

\section{a. Latar Belakang}

Publikasi ilmiah menjadi bagian yang tak terpisahkan pada tiap-tiap perguruan tinggi yang ada di dunia. Tanpa publikasi ilmiah, sulit rasanya sebuah ilmu untuk dikaji dan dikembangkan. Publikasi 
ilmiah merupakan media komunikasi antar para akademisi/praktisi ataupun peneliti terhadap suatu bidang/subjek atau disiplin ilmu. Kata 'ilmiah' yang bersanding pada kata 'publikasi' tentu membedakan publikasi ilmiah dengan publikasi-publikasi lainnya. Ilmiah di sini dimaksud 'memenuhi syarat (kaidah) ilmu pengetahuan' (Setiawan, n.d.). Dengan demikian publikasi ilmiah ialah publikasi yang telah memenuhi syarat/kaidah ilmu pengetahuan.

Berdasarkan data statistik, pada tahun 2014 di Indonesia terdapat 3.246 perguruan tinggi/setingkat perguruan tinggi dengan jumlah program studi 19.373 dan jumlah dosen sebanyak 213.920, baik itu milik pemerintah ataupun swasta (Karna Radjasa, 2016). Melihat data perguruan tinggi yang begitu banyak, tentu saja seharusnya berbanding lurus juga dengan jumlah publikasi ilmiah yang ada di tanah air. Akan tetapi, dari beberapa laporan yang pernah diinformasikan, baik itu media cetak ataupun elektronik, jumlah publikasi ilmiah Indonesia masih jauh di bawah dari beberapa negara tetangga seperti Malaysia, Singapura, dan Thailand yang tentu saja ketiga negara tersebut jumlah perguruan tingginya tidak sebanyak dengan perguruan tinggi yang ada di tanah air (Pendidikan Tinggi, 2017).

Melihat kondisi ini, Menteri Riset, Teknologi dan Perguruan Tinggi (Menristekdikti), Mohamad Nasir menghimbau kepada seluruh akademisi, khususnya para dosen di tiap-tiap perguruan tinggi untuk meningkatkan publikasi ilmiahnya masing-masing, pada bulan Maret 2017 (Hidayat, 2017). Himbauan dengan disertai dengan surat edaran ke pimpinan-pimpinan perguruan tinggi yang ada di tanah air tentang peningkatkan publikasi ilmiah akhirnya memberikan hasil yang signifikan pada peningkatan jumlah publikasi ilmiah tanah air, di mana pada bulan Oktober 2017 publikasi ilmiah Indonesia telah menyalip Thailand (LIPI, 2017).

Berbicara dalam konteks persaingan global, kuantitas dan kualitas publikasi ilmiah menjadi hal yang perlu diamati. Dengan kemajuan teknologi informasi dan komunikasi yang sangat pesat saat ini, dampak sebuah publikasi ilmiah dapat diukur. Istilah Impact Factor (faktor dampak/pengaruh) pada sebuah publikasi ilmiah kini telah dapat dijadikan sebagai alat ukur untuk mengetahui seberapa besar dampak/pengaruh sebuah publikasi ilmiah yang telah dihasilkan oleh seorang penulis atau kelompok penulis, atau media-media publikasi yang ada.

Terdapat beberapa jenis publikasipublikasi ilmiah yang ada di Universitas Islam Negeri (UIN) Alauddin saat ini, khususnya dalam bentuk elektronik/online, di antaranya jurnal ilmiah, majalah ilmiah, tabloid ilmiah, makalah, laporan penelitian, prosiding, dan lain sebagainya. Namun demikian, riset ini hanya difokuskan pada jurnal ilmiah yang ada di UIN Alauddin Makassar. Ini tentu menarik untuk diamati mengingat pada Maret lalu, edaran Menristekdikti juga telah sampai pada pengelola-pengelola jurnal ilmiah UIN Alauddin Makassar.

\section{a) Ruang Lingkup Penelitian}

Sebagaimana yang telah disebutkan sebelumnya bahwa di UIN Alauddin Makassar, terdapat beberapa bentuk publikasi ilmiah. Penelitian ini hanya difokuskan pada jurnal-jurnal ilmiah online yang dapat diakses melalui laman website jurnal tersebut. Dengan demikian, jenis publikasi ilmiah lainnya seperti prosiding, majalah, makalah, dan lain 
sebagainya tidak disinggung pada penelitian ini.

\section{b) Rumusan Masalah}

Sejak digalakkannya publikasi ilmiah melalui Kemenristekdikti, banyak pengelola-pengelola penerbit ilmiah, khususnya jurnal ilmiah antusias untuk menata kelola jurnal-jurnal mereka masing-masing dengan sebaik-baiknya. Begitu pula di kampus UIN Alauddin Makassar, terlihat ada perubahan yang signifikan sejak beberapa bulan lalu. Oleh karena itu, beberapa poin yang menjadi rumusan masalah pada penelitian ini yakni sebagai berikut:

1) Berapa banyak jumlah artikel ilmiah online yang telah dipublikasikan hingga tahun 2017?

2) Berapa kali rata-rata frekuensi terbitan jurnal-jurnal UIN Alauddin?

3) Apa-apa saja subjek jurnal-jurnal ilmiah yang ada di UIN Alauddin?

4) Seberapa besar pengaruh (impact factor) jurnal-jurnal ilmiah tersebut, berdasarkan Sitasi Google Cendekia (Google Scholar Citations)?

5) Apa-apa saja indeks nasional/internasional pada jurnaljurnal yang ada di UIN Alauddin?

\section{c) Tujuan dan Manfaat Penelitian}

Penelitian ini bertujuan untuk menggambarkan tren publikasi jurnal ilmiah online di kampus UIN Alauddin Makassar. Dengan mengetahuinya, tentu saja hasil penelitian ini diharapkan dapat menjadi pedoman bagi UIN Alauddin Makassar guna evaluasi dan pengembangan tata kelola publikasi ilmiah yang disinergikan dengan program-program dari Kemenristekdikti, khususnya yang berkaitan dengan publikasi ilmiah. Selain itu, artikel ini juga dapat menjadi rujukan bagi tiap-tiap pengelola jurnal ilmiah yang ada di UIN Alauddin Makassar sebagai pembanding data tiap-tiap jurnal yang ada di kampus ini. Bagi khalayak ramai, artikel ini juga dapat membantu dalam menginformasikan keberadaan jurnaljurnal ilmiah yang ada di UIN Alauddin Makassar.

\section{d) Definisi Istilah}

Agar tidak menimbulkan ketidakjelasan beberapa istilah pada penelitian ini, berikut diberikan definisi singkat mengenai istilah-istilah yang digunakan;

- Tren, merupakan 'gaya, mutakhir'.

- Publikasi, merupakan 'pengumuman, penerbitan'.

- Ilmiah, merupakan 'bersifat ilmu; secara ilmu pengetahuan; memenuhi syarat (kaidah) ilmu pengetahuan'(Setiawan, n.d.)

Universitas Islam Negeri Alauddin Makassar, adalah salah satu perguruan tinggi di bawah naungan Pendidikan Tinggi Keagamaan Islam, Kementerian Agama, yang juga menyediakan media-media publikasi ilmiah bagi para sivitas akademika

\section{TINJAUAN LITERATUR}

Tren publikasi ilmiah, khususnya pada jurnal ilmiah, menjadi isu hangat sejak beberapa tahun belakangan ini. Pada tahun 2019, oleh Menristekdikti, Indonesia ditargetkan dapat menghasilkan 30 ribu karya tulis ilmiah yang terpublikasi pada jurnal internasional bereputasi (Harapan, 2017). Tentu ini merupakan tantangan, khususnya bagi seluruh peneliti/dosen yang ada di tanah air agar dapat terus menghasilkan karya yang bermutu. 
Pemerintah pun telah berupaya semaksimal mungkin agar bagaimana, melalui karya-karya riset tersebut, Indonesia dapat menunjukkan jati dirinya sebagai bangsa yang kuat. Beberapa kebijakan pemerintah yang berkenaan dengan ini di antaranya Peraturan Menteri Pendayagunaan Aparatur Negara Nomor 17 Tahun 2013 tentang Jabatan Fungsional Dosen dan Angka Kreditnya dan Peraturan Menteri Riset, Teknologi, dan Pendidiktan Tinggi Nomor 20 Tahun 2017 tentang Pemberian Tunjangan Profesi Dosen dan Tunjangan Kehormatan Profesor.

Sebagaimana yang telah diungkapkan sebelumnya bahwa secara kuantitas jumlah karya tulis ilmiah di Indonesia yang terindeks pada mesin-mesin indeks bereputasi internasional masih jauh dibandingkan beberapa negara tetangga lainnya di Asia Tenggara, sementara jumlah perguruan tinggi atau sekolahsekolah tinggi yang ada di Indonesia tentu jauh lebih banyak di banding negaranegara tetangga tersebut. Namun demikian, ada peningkatan statistika pada tahun 2017 ini. Salah satu literatur yang menyediakan kekuatan beberapa institusi/perguruan tinggi yang ada di tanah air memberikan data-data mengenai karya-karya ilmiah yang telah terpublikasi pada skala internasional pada instusi/perguruan tinggi - perguruan tinggi tersebut (Lukman, Yaniasih, Maryati, A. Silalahi, \& Sihombing, 2016).

Sejak 2014 lalu, ada upaya-upaya untuk mengubah paradigma tata kelola jurnal ilmiah, yakni dari versi cetak ke online (Pengelolaan \& Intelektual, 2014). Dengan versi online tersebut, sesuai dengan perkembangan teknologi, karyakarya ilmiah yang terpublikasi dapat disebarkan dengan begitu mudah tanpa dibatasi oleh ruang dan waktu. Salah satu hasil penelitian menunjukkan bahwa beberapa komunitas orang lebih cenderung memanfaatkan jurnal dalam bentuk elektronik/online daripada yang masih dalam bentuk tercetak, selain karena mudahnya diakses, jurnal elektronik juga mudah ditemukan (Sathe, Grady, \& Giuse, 2002).

Berkaitan dengan akreditasi jurnal, Kemenristekdikti telah menyediakan portal khusus untuk akreditasi jurnal yang disebut dengan ARJUNA (Akreditasi Jurnal Nasional) (Ristekdikti, 2017a). Selain itu, pada tahun ini juga telah dirilis SINTA (Science and Technology Index), yakni portal khusus yang dapat digunakan oleh siapa saja dengan mudah untuk mengakses jurnaljurnal yang telah terpublikasi di tanah air, untuk mengetahui para peneliti-peneliti yang ada di tanah air, melihat tren publikasi ilmiah pada suatu bidang ilmu, dan masih ada lagi manfaat lainnya yang tentu saja akan terus berkembang (Ristekdikti, 2017b).

Pada tahun 2015, (Almah, 2015) melakukan kajian tentang eksistensi jurnal ilmiah di UIN Alauddin Makassar. Pada penelitian ini menunjukkan bahwa terdapat 31 jurnal di kampus tersebut telah dapat diakses secara online meskipun belum semuanya telah berisi artikel-artikel yang telah diterbitkan. Hasil penelitian ini akan sangat mendukung tulisan ini, mengingat belum ada kajiankajian terdahulu yang betul-betul meneliti tentang jurnal-jurnal ilmiah di UIN Alauddin Makassar.

Penelitian mengenai tren publikasi ilmiah juga dilakukan oleh Hariyah tentang tren penelitian studi Islam dalam jurnal Badan Litbang dan Diklat Kemenag RI. Penelitian ini menunjukkan kecenderungan subjek-subjek yang sering digunakan pada 1.107 artikel pada jurnal 
tersebut yang terbit antara tahun 20052014 (Hariyah, 2016).

Publikasi ilmiah menjadi hal yang santer dibicarakan akhir-akhir ini. Para pengelola-pengelola jurnal ilmiah di tanah air semakin gencar menata kembali pengelolaan dan penerbitan jurnalya, khususnya mengenai paradigma yang disebutkan di atas tadi. Jumlah publikasi ilmiah pun tiap tahunnya bertambah, yakni dengan mengajukan permohonan ISSN (International Standar of Serial Number) ke lembaga yang diamanahkan untuk menerbitakan nomor tersebut, LIPI PDII (Lembaga Ilmu Pengetahuan Indonesia, Pusat Dokumentasi dan Informasi Ilmiah). Namun demikian, tidak sedikit jurnal-jurnal tersebut konsisten menerbitkan artikel-artikel ilmiahnya tiap tahun. Perlu untuk diketahui bahwa, ISSN ini merupakan syarat mutlak bagi jurnaljurnal ilmiah yang ingin mengajukan akreditasi jurnal.

Pengelolaan jurnal ilmiah kini semakin mudah, apalagi dengan adanya pedoman akreditasi yang telah ada saat ini. Begitu pula jurnal-jurnal ilmiah yang berada di bawah Kementerian Agama, Pendidikan Islam, juga memiliki pedoman akan hal tersebut (Kemenag, 2016). Tata kelola jurnal ilmiah, sudah selayaknya menyesuaikan dengan pedomanpedoman yang ada tersebut, ini tentu dimaksudkan agar publikasi ilmiah terproses dengan kaidah-kaidah yang telah ditentukan guna menerbitkan karya tulis ilmiah yang berkualitas (Nashihuddin \& Aulianto, 2016). Dengan demikian, saat ini tren publikasi ilmiah menjadi isu yang sangat penting di tanah air. Publikasi ilmiah juga menjadi salah satu indikator tingkat kemajuan sebuah negara.

\section{METODOLOGI PENELITIAN}

\section{a) Jenis Penelitian}

Penelitian ini merupakan penelitian deskriptif kuantitatif yakni penelitian yang hanya akan menggambarkan mengenai tren publikasi jurnal online di UIN Alauddin Makassar dengan menggambarkannya dalam bentuk diagram/grafis yang disertadi dengan penjelasan yang semudah mungkin untuk dipahami oleh para pembaca.

\section{b) Sumber Data}

1. Data Primer

Data-data primer penelitian ini diperoleh dari laman berikut ini.

- http://journal.uin-alauddin.ac.id/

- https://scholar.google.co.id/

- https://doaj.org/

- http://www.scimagojr.com/

- http:/ / sinta2.ristekdikti.go.id/

- http://moraref.or.id/

- http://issn.pdii.lipi.go.id/

\section{Data Sekunder}

Data-data sekunder diperoleh dari dokumentasi beberapa pengelola jurnal online ilmiah UIN Alauddin Makassar.

\section{c) Teknik Pengumpulan Data}

Website yang telah disebutkan di atas menjadi sumber utama dalam pengumpulan data-data penelitian ini. Pertama, melalui portal jurnal online UIN Alauddin Makassar akan diketahui ada berapa banyak jumlah jurnal yang ada di kampus tersebut, subjek apa saja, penerbitnya, hingga frekuensi terbitan jurnal masing-masing. Kedua, melalui Google Scholar (GS), penelitian ini akan memperolah tingkat sitasi tiap-tiap jurnal 
(jika memang telah terindex di GS), tingkat h-index dan i10-index masingmasing jurnal. Setelah data-data dari laman tersebut diperoleh, selanjutnya data-data tersebut akan digambarkan dalam bentuk visualisasi grafik dengan menggunakan Ms. Excel.

\section{HASIL PENELITIAN DAN PEMBAHASAN}

Di bawah ini akan digambarkan hasil penelitian dengan berdasar pada rumusan masalah di atas.

\section{1) Jumlah Jurnal di UIN Alauddin Makassar}

UIN Alauddin Makassar merupakan salah satu universitas besar di Wilayah Timur Indonesia. Beberapa universitas besar lainnya seperti Universitas Hasanuddin dan Universitas Negeri Makassar, juga merupakan universitas yang telah memiliki reputasi yang tinggi, nasional maupun internasional. Berkaitan dengan jurnal ilmiah, berdasarkan data yang diperoleh dari situs jurnal elektronik UIN Alauddin Makassar (http://journal.uin-alauddin.ac.id/), ditemukan terdapat 62 jurnal ilmiah yang ada di UIN Alauddin Makassar. Namun demikian tidak semua yang telah ditampilkan pada situs tersebut berisi artikel-artikel ilmiah, akan tetapi dipastikan ada keberadaannya di kampus tersebut. Dari keseluruhan jurnal tersebut ditemukan total jumlah artikel ilmiah sebanyak 2434 artikel yang telah dipublikasikan online hingga November 2017. Sepuluh jurnal yang sangat produktif mengonlinekan artikel mereka dapat dilihat pada diagram lingkaran di berikut ini.

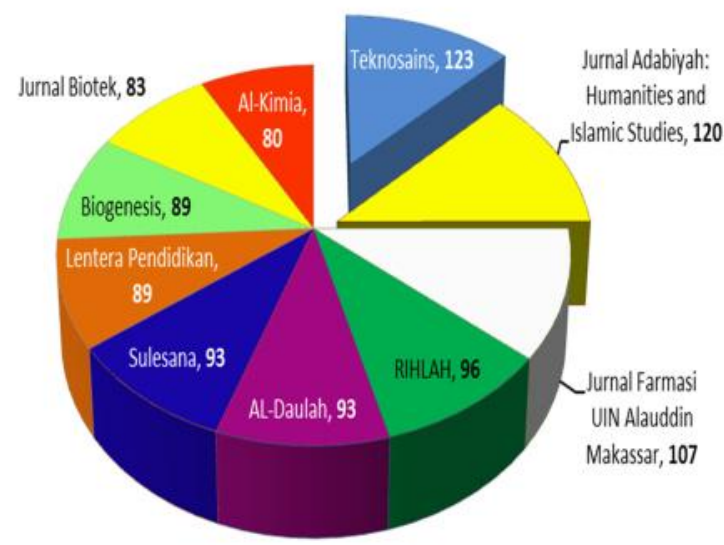

Grafik 1. Sepuluh jurnal terproduktif

\section{2) Frekuensi Terbitan Jurnal}

Berdasarkan data yang diperoleh dari situs http://issn.pdii.lipi.go.id/, rata-rata jurnal yang ada di UIN Alauddin Makassar menerbitkan 2 nomor dalam satu tahun. Pada umumnya terbit di bulan Juni dan Desember, April dan September. HIGIENE: Jurnal Kesehatan Lingkungan merupakan satu-satunya jurnal yang terbit 4 bulanan dalam setahun, yakni pada bulan April, Agustus, dan Desember.

\section{3) Subjek-subjek Jurnal UIN Alauddin Makassar}

Berkaitan dengan subjek/ruang lingkup tiap-tiap jurnal yang ada di kampus tersebut diperoleh melalui laman jurnal elektronik UIN Alauddin Makassar. Akan tetapi, dari ke 62 jurnal yang ada di laman tersebut, tidak semuanya menggambarkan dengan jelas subjek atau ruang lingkupnya masing-masing. Tabel di bawah menggambarkan jurnal berdasarkan subjek atau ruang lingkupnya.

Tabel 1. Subjek-subjek jurnal di UIN Alauddin

\begin{tabular}{|l|l|l|}
\hline No. & Nama Jurnal & Subjek \\
\hline 1 & JICSA & $\begin{array}{l}\text { Studi Islam pada bidang } \\
\text { budaya, masyarakat, } \\
\text { ekonomi, sejarah, dan } \\
\text { doktrin }\end{array}$ \\
\hline
\end{tabular}


Taufiq Mathar, A. Khaidir Akbar, Hijrana Bahar: Tren publikasi jurnal ilmiah online di Universitas Islam Negeri Alauddin Makassar

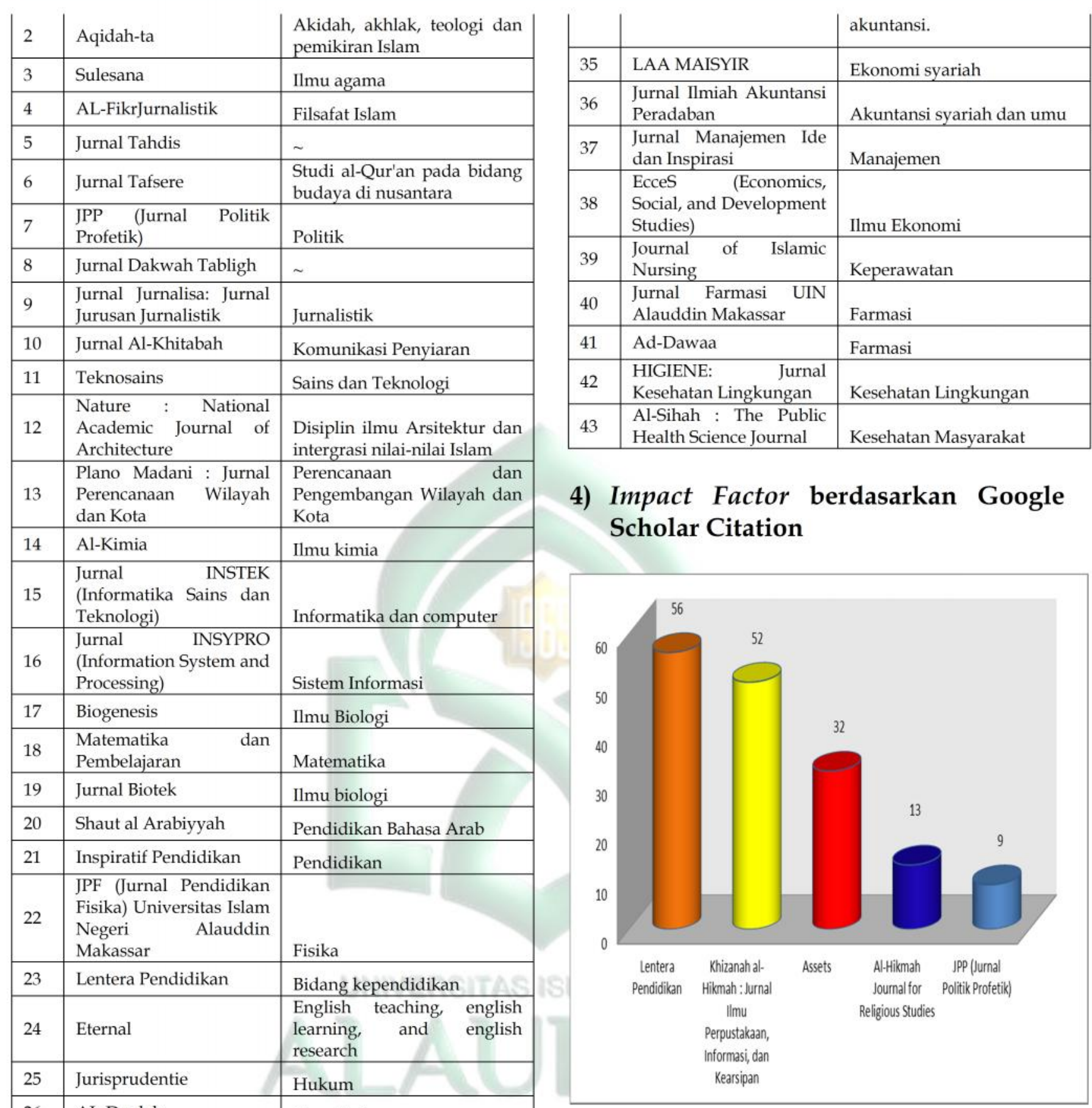

\section{Grafik 2. Lima jurnal dengan kutipan terbanyak berdasarkan Google Scholar Citation}

Gambar di atas menunjukkan 5 jurnal ilmiah yang memiliki sitasi tertinggi dari Google Scholar Citation. Di mana Lentera Pendidikan : Jurnal Ilmu Tarbiyah dan Keguruan menempati urutan pertama, diikuti oleh Khizanah al-Hikmah, Assets, Al-Hikmah, dan JPP. Tentu tren ini akan terus meningkat di tahun-tahun berikutnya. Namun demikian, dari angka h-index dan i10-index, Khizanah al- 
Hikmah menempati urutan pertama sebagaimana yang dapat dilihat pada grafik batang di bawah ini.

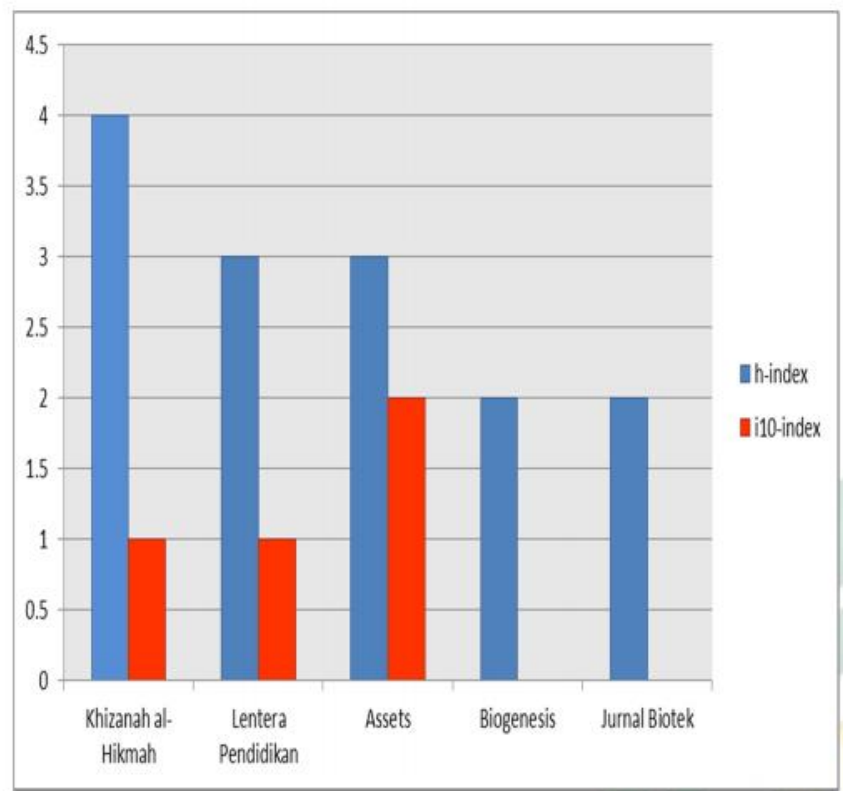

Grafik 3. Lima jurnal dengan h-index dan i10-index tertinggi berdasarkan Google Scholar Citation

\section{5) Indeksasi Jurnal}

Jurnal ilmiah online tentunya memiliki kelebihan tersendiri, yakni dapat tersebar luas dengan sangat cepat di mana dan kapanpun. Salah satu strategi penting dalam mendesiminasikan jurnal ilmiah yaitu dengan menggabungkan diri pada mesin-mesin indeks yang ada saat ini. Tidak dapat dipungkiri, Google dapat dikatakan sebagai mesin indeks situs-situs online yang paling banyak digunakan saat ini. Dari data yang telah dikumpulkan, tidak semua ke 62 jurnal yang ada di UIN Alauddin Makassar terindeks di mesinmesin indeks yang ada saat ini. Pada tabel di bawah ini menggambarkan jurnaljurnal yang telah terindeks di beberapa mesin pengindeks.

Tabel 2. Indeksasi jurnal

\begin{tabular}{|c|l|lr|}
\hline NO & NAMA JURNAL & TERINDEX DI \\
\hline 1 & JICSA & $\begin{array}{l}\text { IPI, Moraref, } \\
\text { Scholar, Soogle }\end{array}$ \\
& & SINTA, Base, \\
\hline
\end{tabular}

\begin{tabular}{|c|c|c|}
\hline & & $\begin{array}{l}\text { CrossRef, Harvard Library, } \\
\text { MAS }\end{array}$ \\
\hline 2 & Aqidah-ta & Google Scholar, Crossref \\
\hline 3 & $\begin{array}{l}\text { JPP (Jurnal Politik } \\
\text { Profetik) }\end{array}$ & Google Scholar \\
\hline 4 & $\begin{array}{lr}\text { Jurnal } & \text { Jurnalisa: } \\
\text { Jurnal } & \text { Jurusan } \\
\text { Jurnalistik } & \end{array}$ & Google Scholar \\
\hline 5 & Jurnal Al-Khitabah & Google Scholar \\
\hline 6 & $\begin{array}{l}\text { Nature : } \\
\text { Academic Jational } \\
\text { of Architecture }\end{array}$ & $\begin{array}{l}\text { Google Scholar, Moraref, } \\
\text { Onesearch, CrossRef, } \\
\text { DOAJ, SINTA, Portal } \\
\text { Garuda, Wordcat, Harvard } \\
\text { Library }\end{array}$ \\
\hline 7 & $\begin{array}{l}\text { Plano Madani : } \\
\text { Jurnal Perencanaan } \\
\text { Wilayah dan Kota }\end{array}$ & $\begin{array}{l}\text { Onesearch, Moraref, IPI, } \\
\text { ESJI, Google Scholar, } \\
\text { BASE, DRJI, Real Time } \\
\text { Factor, Infobase Index, } \\
\text { COSMOS Impact Factor }\end{array}$ \\
\hline 8 & Al-Kimia & $\begin{array}{l}\text { Google Scholar, } \\
\text { Onesearch, Moraref, BASE, } \\
\text { DRJI, CiteFactor, } \\
\text { Scholarteer, Sinta, Crossref }\end{array}$ \\
\hline 9 & $\begin{array}{l}\text { Jurnal INSYPRO } \\
\text { (Information } \\
\text { System and } \\
\text { Processing) }\end{array}$ & $\begin{array}{l}\text { Google Scholar, Moraref, } \\
\text { CrossRef, BASE }\end{array}$ \\
\hline 10 & Biogenesis & $\begin{array}{l}\text { Moraref, Portal Garuda, } \\
\text { Google Scholar, Sinta, } \\
\text { Crossref, } \\
\text { ResearchBib, ESJ, } \\
\text { Scientific Indexing Service }\end{array}$ \\
\hline 11 & $\begin{array}{l}\text { Matematika dan } \\
\text { Pembelajaran }\end{array}$ & $\begin{array}{l}\text { Google Scholar, Moraref, } \\
\text { Crossref, Portal Garuda, } \\
\text { BASE, ISSUU, ResearchBib }\end{array}$ \\
\hline 12 & Jurnal Biotek & $\begin{array}{l}\text { Google Scholar, Moraref, } \\
\text { IPI, SINTA }\end{array}$ \\
\hline 13 & Shaut al Arabiyyah & $\begin{array}{l}\text { Google Scholar, Crossref, } \\
\text { Portal Garuda, Sinta }\end{array}$ \\
\hline 14 & $\begin{array}{l}\text { JPF (Jurnal } \\
\text { Pendidikan Fisika) }\end{array}$ & Google Scholar \\
\hline 15 & Lentera Pendidikan & $\begin{array}{lll}\text { Google } & \text { Scholar, } \\
\text { IPI, Aoraref, } \\
\text { AcacemicKeys }\end{array}$ \\
\hline 16 & Eternal & Google Scholar, Moraref \\
\hline 17 & Jurisprudentie & Google Scholar, Moraref \\
\hline 18 & AL-Daulah & $\begin{array}{l}\text { Google Scholar, BASE, } \\
\text { Moraref }\end{array}$ \\
\hline 19 & $\begin{array}{l}\text { ELFALAKY: Jurnal } \\
\text { Ilmu Falak }\end{array}$ & Google Scholar, Moraref \\
\hline 20 & $\begin{array}{l}\text { Jurnal Adabiyah: } \\
\text { Humanities and } \\
\text { Islamic Studies }\end{array}$ & $\begin{array}{l}\text { Google Scholar, BASE, } \\
\text { Moraref, OneSearch, Portal } \\
\text { Garuda, Open Archives }\end{array}$ \\
\hline 21 & $\begin{array}{l}\text { Khizanah } \\
\text { Hikmah : Jurnal } \\
\text { Ilmu Perpustakaan, } \\
\text { Informasi, dan } \\
\text { Kearsipan }\end{array}$ & $\begin{array}{l}\text { Google Scholar, Portal } \\
\text { Garuda, } \\
\text { OneSearch, } \\
\text { CrossRef, BASE, WINTA, } \\
\text { Harvard Library, MAS, } \\
\text { ISJD, DOAJ }\end{array}$ \\
\hline 22 & $\begin{array}{ccc}\text { Diwan } & \text { Jurnal } \\
\text { Bahasa } & \text { dan } & \text { Sastra }\end{array}$ & Google Scholar \\
\hline
\end{tabular}




\begin{tabular}{|c|c|c|}
\hline & Arab & \\
\hline 23 & $\begin{array}{l}\text { Elite English and } \\
\text { Literature Journal }\end{array}$ & Google Scholar \\
\hline 24 & Jurnal Iqtisaduna & $\begin{array}{l}\text { Google Scholar, } \\
\text { OneSearch, Moraref }\end{array}$ \\
\hline 25 & Assets & Google Scholar \\
\hline 26 & $\begin{array}{l}\text { Jurnal Manajemen } \\
\text { Ide dan Inspirasi }\end{array}$ & Google Scholar \\
\hline 27 & $\begin{array}{l}\text { Journal of Islamic } \\
\text { Nursing }\end{array}$ & Google Scholar \\
\hline 28 & $\begin{array}{l}\text { Jurnal Farmasi UIN } \\
\text { Alauddin Makassar }\end{array}$ & Google Scholar \\
\hline 29 & $\begin{array}{l}\text { HIGIENE: Jurnal } \\
\text { Kesehatan } \\
\text { Lingkungan }\end{array}$ & Google Scholar, Moraref \\
\hline 30 & $\begin{array}{l}\text { Al-Sihah : The } \\
\text { Public Health } \\
\text { Science Journal }\end{array}$ & Google Scholar \\
\hline
\end{tabular}

Terindeksnya sebuah jurnal di mesinmesin indeks yang ada saat ini membantu agar jurnal-jurnal tersebut dapat diketahui oleh siapa saja, baik dalam skala nasional maupun internasional. Dari tabel di atas, tidak semua jurnal yang ada di UIN Alauddin terindeks di mesin-mesin indeks. Namun, beberapa jurnal lainnya ada yang telah terindeks di mesin indeks berskala internasional, artinya jurnaljurnal tersebut dapat dengan mudah terlacak secara global.

\section{KESIMPULAN}

Berdasarkan hasil penelitian yang telah diuraikan di atas, maka dapat disimpulkan sebagai berikut:

1) Hingga November 2017, terdapat 2434 artikel ilmiah yang telah dionlinekan dari 62 jurnal ilmiah yang dapat diakses pada laman resmi jurnal elektronik UIN Alauddin Makassar. Namun demikian, tidak semuanya jurnal telah mengonlinekan artikelartikelnya.
2) Ke 62 jurnal pada laman tersebut merupakan jurnal yang diterbitkan oleh jurusan-jurusan, fakultas, lembaga, serta pascasarjana UIN Alauddin Makassar,

3) Rata-rata tiap-tiap jurnal memiliki frekuensi terbit 2 kali dalam setahun,

4) Lentera Pendidikan, Khizanah alHikmah, dan Assets merupakan tiga jurnal yang paling banyak disitasi,

5) Terdapat 30 jurnal yang telah terindex di beberapa mesin index yang ada, baik dari dalam maupun luar negeri, di antaranya Google Scholar, DOAJ, Moraref, Sinta, Portal Garuda, CrossRef, CiteScore, Base, dan lainlainnya.

\section{DAFTAR PUSTAKA}

Almah, H. (2015). Eksistensi Jurnal Ilmiah di Universitas Islam Negeri Alauddin Makassar (Perannya Dalam Mendukung Universitas Islam Negeri Alauddin Makassar Menuju World-Class University). Khizanah Al-Hikmah: Jurnal Ilmu Perpustakaan, Informasi, Dan Kearsipan, 3(2), 172-184. https://doi.org/10.24252/kah.v3i2a 6

Harapan, S. (2017). Tahun 2019 Target Publikasi " Jurnal Internasional Bereputasi " Indonesia Mencapai 30 Ribu KTI. Sinarharapan.Net. Retrieved from http:/ / sinarharapan.net/2017/01/ta hun-2019-target-publikasi-jurnalinternasional-bereputasi-indonesiaharus-mencapai-30-ribu-kti/

Hariyah. (2016). Tren Penelitian Studi Islam dalam Jurnal Badan Litbang dan Diklat Kemenag RI: Penggunaan Co-Words, 2(6), 162-175.

Hidayat, F. (2017). Menristekdikti Dorong 
Dosen Tingkatkan Publikasi Ilmiah Ristekdikti. Retrieved October 26, 2017, from https://www.ristekdikti.go.id/menr istekdikti-dorong-dosen-tingkatkanpublikasi-ilmiah/

Karna Radjasa, O. (2016). Riset dan Publikasi Ilmiah. Retrieved from http:// risbang.ristekdikti.go.id/revi ewer/20. Paparan Ocky Karna Radjasa - Direktur RPM (Riset dan Publikasi Ilmiah).pdf

Kemenag. (2016). Pedoman Pengelolaan dan Akreditasi Terbitan Berkala Ilmiah (TBI) Perguruan Tinggi Keagamaan Islam.

LIPI. (2017). Mantap! Publikasi Ilmiah Indonesia Berhasil Salip Thailand. Chubu Chiho Kensetsukyoku. Retrieved from http://lipi.go.id/lipimedia/mantappublikasi-ilmiah-indonesia-berhasilsalip-thailand/19187

Lukman, Yaniasih, Maryati, I., A. Silalahi, M., \& Sihombing, A. (2016). Kekuatan 50 Institusi Ilmiah Indonesia: Profil Publikasi Ilmiah Terindeks Scopus. (Lukman, Ed.). Jakarta.

Nashihuddin, W., \& Aulianto, D. R. (2016). Pengelolaan Terbitan Berkala Ilmiah Sesuai Ketentuan Akreditasi: Upaya Menuju Jurnal Terakreditasi dan Bereputasi Internasional. Jurnal Pustakawan Indonesia (Vol. 15). Perpustakaan Institut Pertanian Bogor. Retrieved from http://jurnal.ipb.ac.id/index.php/jp i/article/view/16921

Pendidikan Tinggi, K. R. \& T. (2017). Panduan Bantuan Pengelolaan / Tata Kelola Jurnal Elektronik 2017.

Pengelolaan, D., \& Intelektual, K. (2014). Kebijakan Akreditasi Terbitan Berkala Ilmiah.

Ristekdikti. (2017a). Akreditasi Jurnal Nasional. Retrieved October 28, 2017, from http:/ / arjuna.ristekdikti.go.id/ Ristekdikti. (2017b). SINTA - Science and Technology Index. Retrieved
October 28, 2017, from http://sinta2.ristekdikti.go.id/

Sathe, N. A., Grady, J. L., \& Giuse, N. B. (2002). Print versus electronic journals: a preliminary investigation into the effect of journal format on research processes. Journal of the Medical Library Association: JMLA, 90(2), 235-43. Retrieved from http://www.ncbi.nlm.nih.gov/pub med/11999183\%5Cnhttp://www.pu bmedcentral.nih.gov/articlerender.fc gi?artid=PMC100770

Setiawan, E. (n.d.). Kamus Besar Bahasa Indonesia (KBBI) Online. Retrieved October 26, 2017, from https://kbbi.web.id/ilmiah 